\title{
Computer self-administered screening for substance use in a university health center: a feasibility pilot
}

\author{
Jennifer McNeely ${ }^{1 *}$, Ferdschneider Marcy ${ }^{2}$, J Allison Smith², Sleiter Luke' ${ }^{1}$ Ciotoli Carlo ${ }^{2}$, Leonard Noelle ${ }^{3}$ \\ From INEBRIA 12th Congress, \\ Atlanda, GA, USA. 24-25 September 2015
}

\section{Background}

Unhealthy use of alcohol and drugs poses a significant health problem on college campuses, [1] and student health centers are an under-utilized resource for offering substance use screening and interventions. [2,3] As a strategy for increasing screening rates, we tested the feasibility of incorporating tablet computer self-administered screening into routine care at one university health clinic.

\section{Materials and methods}

During the 3-week study period, all patients presenting for a visit with a participating primary care provider were asked by the receptionist to fill out a 'health screener' in the clinic waiting area Screening tools were the 4-item Substance Use Brief Screen (SUBS), [4] followed by the ASSIST for those who screened positive. [5] Patients gave informed consent and completed screening on a tablet computer, then viewed their results and were given the option of delivering this information to the medical provider.

\section{Results}

Half of the patients presenting for an appointment received the tablet, of which 337 (90\%) consented and completed screening. Rates of past-year unhealthy use were $73 \%$ for alcohol, $43 \%$ for illicit drugs, and $8 \%$ for prescription drugs. Among participants who screened positive for alcohol, 45 (21\%) had moderate-risk use, and $4(2 \%)$ had high-risk use, based on ASSIST scores. Of those screening positive for drugs, 53 (35\%) had

\footnotetext{
* Correspondence: jennifer.mcneely@nyumc.org

'Deptartment of Population Health, NYU School of Medicine, New York, NY, 10016, USA

Full list of author information is available at the end of the article
}

moderate-risk use, and one had high-risk use. Overall, $49 \%$ of all participants elected to disclose results to their primary care provider. Rates of disclosure were significantly lower for those with moderate-high risk drug or alcohol use (31\%) than in those with low-risk use (59\%), $(\mathrm{P}<0.01)$.

\section{Conclusions}

Our findings suggest that university health centers are a good venue for substance use screening and interventions, but there is also a need for interventions that can be delivered outside the health center, or that increase patient motivation to discuss substance use during the primary care visit.

\section{Acknowledgements}

This research was funded by the Center for Drug Use and HIV Research (P30 DA011041).

\section{Authors' details}

'Deptartment of Population Health, NYU School of Medicine, New York, NY, 10016, USA. ${ }^{2}$ Student Health Center, New York University, New York, NY, 10003, USA. ${ }^{3}$ Center on Drug Use and HIV Research and NYU College of Nursing, New York, NY, 10010, USA.

\section{Published: 24 September 2015}

\section{References}

1. Hingson $\mathrm{R}$, Heeren $T$, Winter $M$, Wechsler $H$ : Magnitude of alcohol-related mortality and morbidity among U.S. college students ages 18-24: changes from 1998 to 2001. Annu Rev Public Health 2005, 26:259-79.

2. Nelson TF, Toomey TL, Lenk KM, Erickson DJ, Winters KC: Implementation of NIAAA College Drinking Task Force recommendations: how are colleges doing 6 years later? Alcohol Clin Exp Res 2010, 34(10):1687-93.

3. Foote J, Wilkens C, Vavagiakis P: A national survey of alcohol screening and referral in college health centers. J Am Coll Health 2004, 52(4):149-57.

4. McNeely J, et al: A brief patient self-administered substance use screening tool for primary care: two-site validation study of the Substance Use Brief Screen (SUBS). Am J Med 2015. 
5. McNeely J, et al: Test-retest reliability of a self-administered Alcohol, Smoking and Substance Involvement Screening Test (ASSIST) in primary care patients. J Subst Abuse Treat 2014, 10(14):00025-7.

doi:10.1186/1940-0640-10-S2-O23

Cite this article as: McNeely et al:: Computer self-administered

screening for substance use in a university health center: a feasibility pilot. Addiction Science \& Clinical Practice 2015 10(Suppl 2):023.

Submit your next manuscript to BioMed Central and take full advantage of:

- Convenient online submission

- Thorough peer review

- No space constraints or color figure charges

- Immediate publication on acceptance

- Inclusion in PubMed, CAS, Scopus and Google Scholar

- Research which is freely available for redistribution

Submit your manuscript at www.biomedcentral.com/submit
C Biomed Central 